\title{
From Necker Cubes to Polyrhythms: Fostering a Phenomenological Attitude in Music Education
}

\author{
Dylan van der Schyff, Faculty of Education, Simon Fraser University \\ Email: dva5@sfu.ca
}

\begin{abstract}
Phenomenology is explored as a way of helping students and educators open up to music as a creative and transformative experience. I begin by introducing a simple exercise in experimental phenomenology involving multi-stable visual phenomena that can be explored without the use of complex terminology. Here, I discuss how the "phenomenological attitude" may foster a deeper appreciation of the structure of consciousness, as well as the central role the body plays in how we experience and form understandings of the worlds we inhabit. I then explore how the phenomenological attitude may serve as a starting point for students and teachers as they begin to reflect on their involvement with music as co-investigators. Here I draw on my teaching practice as a percussion and drum kit instructor, with a special focus on multi-stable musical phenomena (e.g., African polyrhythm). To conclude, I briefly consider how the phenomenological approach might be developed beyond the practice room to examine music's relationship to the experience of culture, imagination and "self."
\end{abstract}

Keywords: Philosophy of Music Education; Phenomenology; Drumming; Music and Consciousness; Embodiment.

\section{Introduction}

The ability to perceive oneself during the process of participation is an essential quality of the aesthetic experience; the observer finds himself in a strange, halfway position: he is involved, and he watches himself being involved. However, this position is not entirely nonpragmatic, for it can only come about when existing codes are transcended or invalidated. The resultant restructuring of stored experiences makes the reader aware not only of the experience but also of the means whereby it develops. Only the controlled observation of that which is instigated by the text makes it possible for the reader to formulate a reference for what he is restructuring. Herein lies the practical relevance of aesthetic experience: it induces this observation, which takes the place of codes that otherwise would be essential for the success of communication. (Iser, 1980, p.134)

This quote from Iser's phenomenology of reading draws out a necessity common to all modes of aesthetic activity. Indeed, "text" and "reader" could just as easily be replaced with "painting" 
and "viewer" or with "music" and "listener." Whatever the case, imagination and reflexive involvement are prerequisites for fully experiencing and appreciating all forms of art. This insight implies even deeper commitments in the context of creative praxis and education: if the function of the arts is to open up previously unrecognized possibilities for experiencing, understanding, and engaging with the relationships that constitute the physical and sociocultural environments we inhabit, then arts educators must develop pragmatic ways of sharing this phenomenological responsibility with students (Greene, 1995). This is particularly challenging in music education. In order to participate effectively musicians must seamlessly integrate and develop a wide range of embodied experience: large and small motor actions; affective-emotional responses; complex and changing patterns of sound; as well as interactions with the immediate physical and social environment in which they find themselves. The musician must also comprehend, on some level at least, the larger socio-cultural implications of what it means to participate in a given musical event, as well as the relevance of this for their own identity and sense of self. For educators, this means that simply transmitting technical knowledge and getting students to play things "correctly" is not sufficient. Involved creative music making requires the musician to become acutely aware of the process of participation from multiple perspectives and to be able to develop new understandings of the shared musical worlds being enacted. Otherwise, the impressions, embodied activities, and evolving interplay of forms and emotions that constitute the aesthetic experience will remain vague and unrefined, and the musician will continue to depend on narrow, codified or externally dictated ways of understanding. As Dewey (2005) writes,

There is work to be done on the part of the percipient as there is on the part of the artist. The one who is too lazy, idle, or indurated in convention to perform this work will not see or hear. His "appreciation" will be a mixture of scraps of learning with conformity to norms of conventional admiration $[\ldots]$. (p. 56)

What can we offer our music students so that they may better deal with such challenges? What kinds of conceptual tools can we present in the context of music instruction that will help students become more reflective, open minded, creative and engaged interpreters, composers and improvisers? How can we help them "see" beyond standard practices and codified understandings to develop their own unique approaches to music making and thus participate more effectively in society as the cultural agents they are? These questions seem more relevant than ever in today's fast changing world, where the development of flexibility of mind is so necessary in order to deal with the conceptual boundary-crossing and creative innovation students will need in their later professional practice. As Greene (1995) writes, we need to find ways of enabling students "to be personally present to their own learning processes and selfreflective with regard to them" (p.181).

As a philosophy of experience, phenomenology would appear to be a good starting place for examining musical experience and learning, and for developing such creative flexibility. Indeed, phenomenology is sometimes referred to as a philosophy of pure possibility (Casey, 2000). However, much of the core literature in phenomenology is notoriously difficult. Like any established intellectual endeavor, phenomenology has developed its own unique "tribal language," making its central texts (e.g. Husserl, 1960, 1970; Heidegger, 1962; Merleau-Ponty, 2002) almost impenetrable for the novice reader. In response to this problem a number of educators (e.g. Ihde, 1977) have developed "experimental" approaches to learning phenomenological methods, where students are first introduced to phenomenology by actually doing it. In this way, when theory and terminology are introduced they are discussed within an experiential (and experienced) context and key ideas and vocabulary are much easier to grasp. This experimental approach to phenomenological inquiry receives little attention in music 
education. However, as I discuss below, it offers a useful way of initiating a reflective approach to musical practice that may developed by the student as a life-long project. ${ }^{1}$

I begin by introducing a simple exercise in experimental phenomenology involving multi-stable visual phenomena (the Necker Cube) that can be explored without the use of complex terminology. In doing so I discuss how the phenomenological attitude may open up a deeper appreciation of the structure and modes of consciousness. To develop this further, I then consider the central role the body plays in how we experience and form understandings of the worlds we inhabit, with a special focus on rethinking received notions of what "aesthetic" experience entails. Following this, I explain how the phenomenological attitude may serve as a starting point for music students and teachers as they begin to reflect on their involvement with music as co-investigators. Here I draw on my teaching practice as a percussion and drum kit instructor in an undergraduate music program, developing the pedagogical possibilities of multi-stable musical phenomena (African polyrhythm) in line with the phenomenological framework explored in previous sections. While I do not discuss a "study" as such, the reader may nevertheless begin to explore the examples on offer immediately and evaluate the process for themselves within the reflexive phenomenological context I provide. Furthermore, although my discussion is mostly situated within the context of postsecondary instrumental music education, I hope that many of the ideas I put forward here will be adaptable across a range of contexts. With this in mind, I conclude the paper by briefly considering how the phenomenological approach might be developed beyond the practice room to examine music's relationship to the experience of culture, imagination and "self."

\section{Practicing phenomenology with "multi-stable" images}

Students enter undergraduate music programs with varying degrees of skill and musical understanding. By this point they will all have had some experience playing in ensembles, taking lessons, and engaging in some sort of private practice. Many will also have participated in so-called informal musical practice and learning with friends and family members. For the most part, students come to understand the process of music making in terms of what workswhat will get them through the performance and win them the approval of teachers, band-mates, and friends. Put simply, music making at this stage is pragmatic (in the more superficial sense of the word) and in many ways it makes sense that it should be so. However, students may become locked into ways of understanding musical experiences that are vague, narrow, repetitive, or even dogmatic. Indeed, while many early childhood music education programs maintain a rather playful and creative approach to musical development, in high school and university more conformist attitudes tend to dominate. This often involves a focus on prescriptive (and often competitive) performance practice associated with the "correct" reproduction of "works" (Elliott \& Silverman, 2015). As a result, students often enter private music lessons and ensemble situations at the post-secondary level seemingly oblivious to the idea that there might be a myriad of possibilities for experiencing and understanding even the simplest of musical activities. Others appear to have more awareness of possibilities but have no idea where to begin. Whatever the case, as music educators it is our task to help open new possibilities for musical experience whereby students will be able to develop new knowledge and understandings - to help raise conscious awareness beyond taken-for-granted ways of experiencing the world, develop the creative imagination, and thus foster a sense of agency. In

\footnotetext{
${ }^{1}$ While phenomenological approaches form a major part of qualitative research in the social sciences, psychology and education (Creswell, 2014; van Manen, 2014), my goal here is to introduce how phenomenology may be applied in a more "radically empirical" context - how it may offer a useful way of researching one's own lived experience and for expanding the possibilities of what that might entail.
} 
brief, we must be able to help our students better understand the nature and structure of (musical) experience so that they may engage with it more fully as the creative, world-making beings they are.

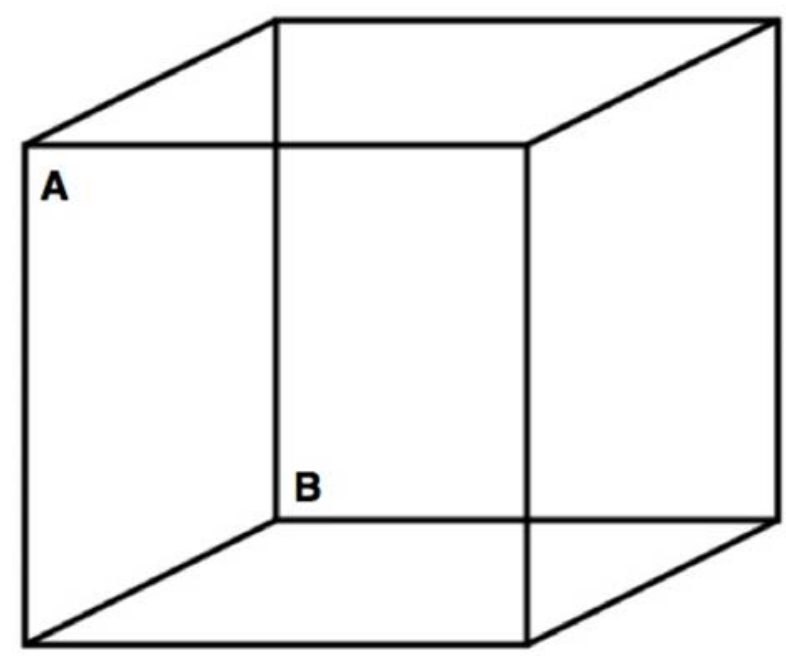

Figure 1. The Necker Cube

One way to begin this project is through the introduction of simple phenomenological exercises involving "multi-stable images" (see Ihde, 1977; Merleau-Ponty, 2002; Roholt, 2014; Christensen, 2012). For example, Figure 1 shows a form known as the Necker Cube (Necker, 1832). This image is well known in psychological circles as an example of a "bi-stable" phenomenon-perception of the image spontaneously reverses itself between two threedimensional spaces (Attneave, 1971; Morris, 1971). Very often, viewers will first experience the cube as if they are oriented above it with a square on the left facing "forward" (A). This is not surprising as similar objects in our day-to-day lives (tables, bricks, chairs, boxes) are generally viewed and interacted with from such a perspective (i.e. above). However, the cube may also be perceived from "below" with a square facing towards the viewer's right (B) and when looked at for a period of time it will often appear to "shift" unpredictably between the above and below perspectives. With a bit of practice, the viewer can hold on to and learn to move willfully between the above-left and below-right points of view.

The phenomenological approach allows us to develop our experience of the image still further. By suspending (pre)judgements and explanations, and by focusing on a clear description of the phenomena at hand, the viewer may begin to develop a deeper awareness of the possibilities of the experience, as well as the process of experience itself. I have already suggested that our tendency to experience the Necker Cube first as a "cube" and not in some other way is indicative of the natural attitude (Husserl, 1960; Merleau-Ponty, 2002) we adopt in our encounters with analogous objects in our day-to-day lives. However, by identifying this taken-for-granted perspective we may attempt to suspend or "bracket" it (epoché) and thus open up previously unrecognized possibilities. By suspending the form's "cubeness" the viewer may explore, experiment with and describe the object of experience from a variety of new focal points; by moving habitual perspectives into the background other relationships and interpretations may begin to come forward. One possibility that emerges is that the intersections of lines may now be experienced in a two dimensional context (Christensen, 2012; Ihde, 1977). From this perspective one may notice the vertically oriented rectangle at the center of the image, which is bounded by two right triangles, on the top left and bottom right respectively, and 
trapezoidal figures above, below, left and right. The result is a strange "belt" shape with a hexagonal exterior and rectangular interior; an abstract image with no deeply sedimented relationship to everyday experience. Interestingly, this "flat" perspective is "uncomfortable" and considerably harder to maintain than the cube experience. However, with practice the viewer can learn to make controlled movements between above-left and below-right cubes and the two dimensional "belt." One can blend the three together in in-between states or hold various features of each in place while allowing the rest of the figure and the viewer's relative "position" to move to other orientations. What was formerly bi-stable now becomes multistable and transitional states may be identified. More experimentally minded viewers may now catalogue the results of such investigations in order to build up a richer description of the possible experiences the Necker Cube affords (see Ihde, 1977; Mereau-Ponty, 2002).

Although more could be said here about the Necker Cube and other multi-stable images, what has been discussed thus far already allows us to investigate some fundamental aspects of experience that might normally not be considered. First, we tend towards naturalized ways of organizing the relationships that constitute experience. These are informed (sedimented) by our histories as embodied and ecological (i.e. "located" or "situated") creatures - e.g. the tendency to position ourselves in relation to the image (above, below, facing). Thus a sense of movement and/or bodily orientation in space (whether actual or imagined) is a central aspect of experience (Benson, 2001; Dewey, 2005; Johnson, 2007). Second, the awareness of even the simplest phenomena may be extended beyond the initial taken for granted perspective (the natural attitude) through a reflexive open-ended exploration of possibilities. And third, conscious experience is not simply the retrieval of a preexisting environment (the attitude of objective thought; see Merleau-Ponty, 2002, pp.77-83), rather it is an emergent, constructive or "enactive" process (Maturana \& Varela, 1998; Varela et al., 1993). This last point is especially relevant when we consider that the Necker Cube is not a cube at all but rather 12 lines that intersect in various ways and that the mind projects in three-dimensions. Nevertheless, from a radically empirical point of view the experience of "cubeness" (as well as its variations) is quite real and requires no further proof of validity; we can return to it repeatedly (the phenomenon is apodictic).

\section{Intentionality and the modes of experience}

In addition to the points outlined above we may now discuss a perhaps even more fundamental observation, namely that there appears to be a "directedness" to experience (intentionality) i.e. "if I experience at all I experience something and do so in a certain way" (Ihde 1977, p.43; Merleau-Ponty, 2002). Or, to put it another way, consciousness is always consciousness of some thing as something (Gallagher, 2012). Indeed, we began with an awareness of the "cube," which was experienced literally as such. However, an exploration of how we consciously attended to the cube expanded the possibilities of experience to the point where the image was no longer experienced as a cube at all. We began to move from the prescriptive "literal mindedness" of the natural attitude or taken-for-granted stance (non-reflective/constrained) towards the "polymorphic mindedness" (reflective/open to possibilities) of the phenomenological attitude (Ihde, 1977).

The first thing we may note about this move is that a certain degree of self-awareness or reflexivity was needed in order to recognize the taken-for-granted stance and to develop alternative points of view. It brought into play my location in relation to the object (and/or the object's location in relation to me); it entailed $m y$ struggle to develop other perspectives and $m y$ awareness or involvement in the exploration and construction of experience. This said it is also important to recognize that the "I" is not always explicit or thematized in experience (Ihde, 1977; Benson, 2001; Varela et al., 1993). Indeed, in most mundane experience we are often 
outside of ourselves "in the world of [our projects]" (see Ihde, 1977, p. 47; Merleau-Ponty, 2002). This is to say that in most of the everyday activities we engage in require the development of a repertoire of skills (seeing, hearing, doing) and ways of thinking that we come to take for granted-e.g. cooking, chopping wood, playing and listening to music. Such modes of experiencing (skillful coping) are not lacking in awareness per se but are not those in which we are explicitly self-conscious. Moreover, intense modes of experience where one is almost completely immersed in the experience itself can be pleasurable and rewarding; they may lead to "positive modes of absorption" that are central to aesthetic experiences and that may ultimately afford an expanded and shared sense of self, as well as the cultural and therapeutic benefits that follow (Benson, 2001). By contrast, modes of experience where acute selfawareness dominates can be uncomfortable. Such experiences may be associated with boredom, loneliness, isolation, as well as with physical and psychological pain. Extreme examples of this are found in experiences of forced confinement and torture - under such conditions one might say that the system of experience is narrowed, confined, or trapped within the self: extended consciousness is restricted; descriptive, imaginative, and narrative capacities are reduced; and a sense of dislocation or alienation from one's social, physical or bodily milieu dominates (Benson, 2001).

Everyday experience tends to move between the objects of experience, an awareness of the situations we find ourselves in, and a shifting sense of our own agency (the noematic to noetic; see below). Indeed, we engage in alternating periods of absorbed consciousness and self-consciousness often without reflecting deeply on how such states of awareness arise or where they could lead. For example, we may consider here how a more reflexive or self-aware mode of experience may emerge out of a state of absorption due to an unforeseen occurrence. This might involve a breakdown in whatever tools one is using (a broken string or hammer; see Heidegger, 1962), or an unexpected event in the environment (a dropped glass; the sound of an alarm; a wrong note played in the woodwind section; a dropped beat by the drummer; an audience member creating an annoying disturbance). It may also be noted how a heightened and uncomfortable level of sustained self-awareness, and even temporary feelings of alienation, and psycho-physical discomfort often emerge when we are required to learn new skills-i.e. new ways of thinking, perceiving and doing. We saw this in a very simple context when we tried to advance the possibilities of the Necker Cube (more on this shortly in a musical learning context). Although such experiences may not always bring the "self" to mind explicitly, they nevertheless involve a shift in the mode of experience and therefore demand a level of phenomenal reflection. Such reflection moves towards the how of experience and highlights the agency of the experiencer (What's going on? What am I doing here? How can I fix this? What am I doing wrong? Why is this so difficult?).

Thus, while the starting point of experience is the "something" that is experienced (e.g. the "cube"), the conscious agency of the "I" moves towards the foreground of awareness when we are encouraged to examine and interpret experience. This, in turn, allows experience to be developed beyond its initial state. And indeed, we need not wait for dramatic events such as I have just described to initiate reflexive shifts in our awareness or modes of experiencing - one may actively and creatively choose to develop the mode of experiencing from one that is more absorbed to one that is more reflexive and back again. Again, Dewey (2005) puts it well when he writes:

[A]bsorption in a work of art so complete as to exclude analysis cannot be long sustained. There is a rhythm of surrender and reflection. We interrupt our yielding to the object to ask where it is leading and how it is leading there. (p. 150) 
Likewise, one may also actively shift the focus of attention to differing areas within the field of experience and consciously work on developing new relationships between them. Recall that in order to advance the experience of the Cube the viewer was required to develop new focal points and to practice moving others into the background. However, although the focus of experience may have been on developing the "topography" of the image itself, some residual awareness of the total field of experience was never far off. Thus a central aspect of phenomenological analysis involves making distinctions between those things that lie in the foreground or core of experience, those that lie in the background, and those that occupy the fringes of perception (closer to the horizon of experience). Here a viewer might experiment with expanding, shifting or sharing the core of experience with other objects present in the environment at large; he or she might try viewing the image at distance while simultaneouslyalternately attending to other objects, sounds, physical movements and so on while noting changes in character of the experience.

To summarize, phenomenological inquiry may be understood as an examination of the structure or "directedness" of experience that begins with the what of experience as it appears in the "literal," non-reflective, or taken-for-granted experience of things (the natural attitude). This inquiry then questions retrogressively from the what of appearance to the how (consciousreflective development of the possibilities and modes of experience); and that ultimately develops back to the who of experience (an awareness of the "self" as an active embodied agent in the construction of experience). The schema in Figure 2 is adapted from Ihde (1977).

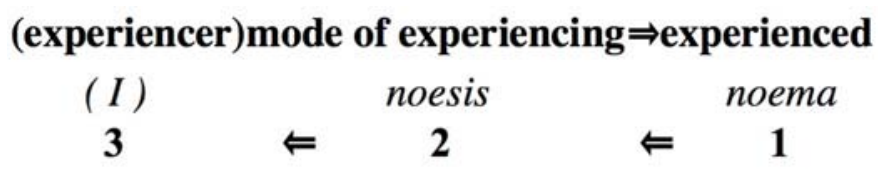

Figure 2. The circularity of experience. ${ }^{2}$

By this view consciousness is understood as a "circular" process that continually moves between the poles of "experiencer" and "experienced,", where the "I" as a full-blown embodied awareness of self comes "late" to experience. In other words, the "situatedness" of the self and its sense of being is an ongoing reflexive process; its relative significance is enacted "through its encounter with things, persons, and every type of otherness it may meet" (Ihde, 1977, p. 51; this is why it is placed in parentheses in Figure 2). The self therefore cannot be pinned down as a fixed entity, but rather appears as an emergent phenomenon, inextricable from embodied organism-environment interactions that give rise to it (Thompson, 2007; Varela et al, 1993).

Put simply, phenomenology provides a means by which we may begin to develop the experience of any number of phenomena through a recognition of the taken for granted ways we attend to them, and therefore open up alternative possibilities. And of course, this may involve the integration of many more perceptual modes (auditory, tactile, bodily, emotional, social and so on) than the almost purely visual dimension that characterized our exploration of the Necker Cube. Indeed, creative engagement with music necessarily involves cross-modal, embodied and intersubjective forms of awareness and attention sharing (Clifton, 1976; Johnson,

\footnotetext{
2 The terms noesis and noema originate in the Greek word vó $\mu \alpha$, which refers to the "aboutness" of a given thought. They were introduced in phenomenology by Husserl (1913) to distinguish the basic (and inseparable) elements of conscious thought or "intentionality." Put very simply, noesis (or the noetic) refers to the mental act of perceiving something in a certain way, while noema (or noematic) concerns the intended object of experience. These terms have been developed by various ways by a range of thinkers (Woodruff Smith, 2007, pp. 304-306; see also Sokolowski, 2000; Solomon, 1977).
} 
2007; Leman, 2007). For example, as a listener one might decide to focus on specific instruments in an ensemble - perhaps one that normally plays a background role - and thus develop a new perspective on a well-known piece of music. In doing so one could also actively seek out new aspects (overtones, harmonics, rhythmic and dynamic nuances and so on) in order to develop the experience of the sounds one engages with (Roholt, 2014). Additionally, one could attend to the sonic properties of the space one occupies (acoustics, reflections, reverberation, diffusion; Ihde, 1976; Blesser \& Salter, 2006). Along these lines, a "focus, core, field and fringe" delineation similar to the one discussed above is taken up in an auditory/musical context by Ihde (1976; see also Schafer, 1986, 1994; Machin, 2010), who points out that unlike visual experience, the auditory field is omnidirectional and explicitly temporal. In this way, musical experience arguably surrounds, permeates and transforms our being in a way that visual experience does not; even in seemingly "passive" listening contexts it actively engages the body and does not first impose a strict subject-object separation. This observation is developed by Clifton (1976) in a listening context, "I intend, or tend-toward the object of feeling, but at the same time submit to it by allowing it to touch me. Possession itself is thus two-directional: I possess the music, and it possesses me" (p. 76).

This all adds an interesting musical dimension to the rhythm of absorption and reflection described by Dewey (above). It also highlights the fundamental existential experience of actuality and potentiality, of coming-into and going-out of being - the continually transforming nature of experience (van der Schyff, 2015). Among other things, such insights may encourage a more nuanced awareness of time perception, where the focus may shift from the narrow (onsets and the "trailing off" of sounds) to the broad (the evolution of a tone or form). This may also involve an exploration of the relationships between the "just past" to the anticipation of what is to come next, the retentions and protentions that characterize the temporal nature of intentionality (Husserl, 1991; Merleau-Ponty, 2002). In connection with this, one could examine how perception of the various attributes of the musical sound develop in relation to bodily-emotive states (i.e. synaesthetic perceptions of movement, location, space, texture, feeling; see Clifton, 1976; Johnson, 2007, Merleau-Ponty, 2002). Similarly, as a performer, one might explore how experience is transformed through the embodied agency of those with whom we co-enact musical worlds (Reybrouck, 2005; Krueger, 2014). Or indeed, one could begin with an examination of sedimented conventions and attitudes in the cultural context (e.g. Small, 1999; Clayton et al., 2011), examining one's relationship to them and considering alternative ways of thinking.

In brief, all of these activities involve a process of moving from taken-for-granted ways of listening, perceiving and thinking towards a more reflective, present or "mindful" attitudeone that may foster more pluralistic, relational and imaginative ways of attending to the world (van der Schyff, 2015). What is important to recognize here is that while the phenomenological attitude seeks to draw out such previously unrecognized aspects of experience it does not reduce experience to such aspects. That is, in contrast to the categorizing trends in empirical science, phenomenology maintains a holistic and relational perspective that strives to develop a greater understanding of the unity of experience as a complex, living, transforming, embodiedecological phenomenon-albeit one that may be attended to and developed from a range of interacting perspectives (Clifton, 1975).

\section{Embodiment and the primordial meaning of aesthetic experience}

As I have begun to consider, phenomenological inquiry affords a deeper understanding of how experience happens in a relational, ecological and living-embodied context (Benson, 2001; 1966; Krueger, 2011, 2013, 2014; Merelau-Ponty, 2002). This reveals that what is experienced 
(noema) cannot be separated from the mode(s) of experiencing (noeisis) as well as the embodied "I" (ego) who reflects upon experience and who forms the (interpretive) historical background narrative that gives it meaning (Gallagher, 2012; Benson, 2001). By this light, the what, how and who of experience stand in an evolving, reflexive, and co-emergent relationship to each other and to the background context with which they are inextricably enmeshed. As Benson (2001) points out, the self, body and world are "of a piece, albeit a very big piece" (p. 31).

Here it should be noted that while conscious experience may be understood as explicitly "object directed," phenomenological inquiry also reveals that there is a strong sense in which all experience may be understood as passively motivated. It is important to understand that in this context the term "passive" is not synonymous with "inactive." Rather, it refers to a fundamental openness to the world - to how the lived body actively constitutes its relationship to the environment though primordial, affectively motivated (or affectively valenced) activity, resulting in patterns of behavior, dispositions and moods, recurrent affective episodes (i.e. emotions), memories, habits and so on (Colombetti, 2014; van der Schyff, 2015). Phenomenologists sometimes use the term "passive synthesis" to describe this process, which is explored to better understand how the object-directed (or "intentional") structure of experience discussed above (I-noesis-noema) emerges from more primordial ways of being-inthe-world that do not always entail an explicit correlational subject-object structure (Thompson, 2007, pp. 28-31; see also Carman, 2008; Gallagher, 2012; Merelau-Ponty, 2002).

Among other things, this (re)reveals an understanding of "aesthetic experience" that goes much "deeper" than the rather detached, rationalizing and analytical approach inherited from Enlightenment thinking (Johnson, 2007). It brings us closer to the original Greek notion of aesthesis, which is grounded in the senses. Indeed, from the phenomenological perspective, aesthetic "sense-making" is primordially rooted in our embodied nature - in feeling, moods, emotion, movement and affectively motivated action; in our non or pre-linguistic capacities for developing relational cross-modal understandings of the worlds we are involved with (Johnson, 2007; Sheets-Johnstone, 1999). It is thus understood as a fundamental way we structure experience as embodied, empathic and social animals beginning at the earliest stages of life. Increasingly, musicality is seen as a primary example of such aesthetic forms of primordial meaning-making, including the embodied forms of "participatory" musical sense-making that occur between infants and caregivers ${ }^{3}$ (Jaegher \& Di Paolo, 2007; DeNora, 2000; Trevarthern, 2002). Put simply, such research highlights the interpretive, empathic-relational, embodied, and improvisatory character of such primary forms of aesthetic meaning-making. In doing so, it reveals a much more nuanced and embodied view of what musicality entails, as well as its deep significance for human development and well-being beginning at the earliest stages of ontogenesis.

The point I would like to stress here is that even at the primordial origins of embodied awareness associated with "passive synthesis", experience (musical or otherwise) is not pregiven. It does not simply involve things "out there" with objective relationships and meanings that are to be perceived and processed "in the head." Rather it is an enactive process that develops though the embodied interactivity between an organism and its environment (Thompson 2007; Varela et al., 1993). And as I have just mentioned, "environment" may also include other agents, where experience and meaning-making becomes a co-operative or "negotiated" process (Fantasia et al., 2014). Again, this speaks to the "extended" nature of musical cognition as a shared phenomenon, where worlds of meaning are brought forth though embodied intersubjective (musical) action-as-perception (see also Reybrouck, 2005).

\footnotetext{
${ }^{3}$ In such interactions infants are no longer understood as simply responding passively to (or simply imitating) pre-given stimuli in the environment. Rather, they actively co-create a repertoire of (musical) sounds and movements that facilitate meaningful interactions with the primary caregiver (Fantasia et al., 2014; see also Krueger, 2013).
} 
Despite the primacy of such relational aesthetic-embodied processes, however, our awareness of such modes of being-in-the-world often becomes obscured. This is partially due to the fact that while our embodiment provides the very means and context by which all experience takes place, in much of day-to-day life the body tends to "hide out" (Johnson, 2007) or retreat into the background of consciousness as our intentionality is directed "out into the world" (Polyani, 1969; Gallagher, 2005). This may also be exacerbated by what Heidegger (1962) sees as our reluctance to own up to our fundamentally interpretive way of being. This involves the anxiety associated with the realization we are not objects with fixed essences and relationships to the world, but rather fundamentally self-interpreting creatures "all the way down" who are nevertheless socialized into particular understandings of being (Dreyfus, 1991). Thus the often-tacit fear of the groundlessness inherent to human existence leads us to become attached to certain ways of being-in-the world that come to be seen as normative - as wholly constitutive of a given experience (the naturalized ways of attending to the world I began to discuss above).

Of course such naturalized attitudes are, in many ways, necessary for day-to-day coping in the world - they are an essential part of the structure of human being (Heidegger, 1962; Dreyfus, 1991). However, when simply taken-for-granted they may also narrow the possibilities of human experience. In this way, our fundamental embodied openness to the world becomes sedimented into rigid ways of perceiving and knowing that come to be misinterpreted as having some kind of essential or fixed ontological status. This often involves the formation of reified notions of what are in reality relational dynamic processes (e.g. mind, self, music, education, culture, emotions, knowledge and so on; see Bai, 2001, 2003; van der Schyff 2015). With this in mind, encouraging a deeper phenomenological awareness of the embodied and transformational processes and perceptions that allow us to make sense of the world may help raise our consciousness to see that experience need not be understood simply in terms of the mental recovery of a pre-given world out there - fixed ways of doing, thinking and perceiving - but rather as arising from our histories of interaction with the (physical, social, and cultural) environment. Indeed, from this perspective experience may begin to be explored in an active and relational context-i.e. in terms of shared worlds that we "open up" or "disclose" for ourselves and each other, and that we may transform through interactive and transformative practices like art and music making (Dreyfus \& Kelly, 2011; Borghman, 1984; Greene, 1995). As the words of Iser and Dewey (above) suggest, such activities allow us to consciously participate in the imaginative restructuring of experience beginning at the most fundamental levels of embodied being-in-the-world - where, again, experience is revealed as a situated, enactive embodied-ecological circularity (Varela et al., 1993; Thompson, 2007).

Importantly, this embodied view stands in contrast to many assumptions common to Western academic musicology, aesthetics and music psychology, which often tend to understand musical experience first in terms of depersonalized cognitive responses to specific (objective) features intrinsic to the musical "work" or performance thereof (Bohlman, 1999; Elliott \& Silverman, 2015; van der Schyff, 2015). As Roholt (2014) points out, this standard analytical perspective artificially brings certain elements to the foreground and treats them as determinate quantifiable phenomena (pitch, timing, structure and so on), effectively putting other elements out of play. In musical contexts this generally involves the assumption that musical experience occurs according to a linear schema, whereby specific objective antecedents intrinsic to the "music itself" (the score or performance) are understood to cause responses in listeners in a more or less passive, disembodied and decontextualized sense. Put simply, the analytical perspective tends to ignore the active modes of experiencing; it focuses on developing "objective" points of view and thus can only describe the more complex relational qualities of subjective musical experience as "ineffable" (Roholt, 2014). This is not to say that such categorical forms of analysis, whether in psychological or musicological contexts, have 
no role to play in music education (e.g. as heuristic tools). However, when wholly decoupled from an exploration of the broader contextual or embodied-situated aspects of experience they offer only a limited (and often misleading) perspective on what musical experience entails. Indeed, it is important to recognize that such objectivist points of view are not based in any fundamental lived reality. Rather they are the products of the theorist-something left over when we inhibit actual lived involvement with the world (Dreyfus, 1991; see also Clifton, 1983; Roholt, 2014).

As we saw with the Necker Cube, and as we will see shortly with African polyrhythm, the features that contribute to the experience of music are not simple, fixed or discreet. Rather they are indeterminate or equivocal - their relative meanings shift due to the active and embodied nature of perception (Bowman, 2004). Thus while the phenomenological approach does seek to draw out and analyze the manifold elements that constitute a given phenomenon, it does so in order to build up a rich account of experience as a relational process that unfolds in time and in specific contexts. Indeed, phenomenology describes the transforming quality of experience through the careful use of metaphor and comparison (see Clifton, 1976; Johnson, 2007; Roholt, 2014; van Manen, 1990, 2014). In the process it embraces the active circular relationship between action and perception (Nöe, 2006), highlighting the purposive, creative and interpretive nature of musical behavior (listening, performing, composing, improvising); as well as the interactive bodily or "motor intentionality" at the root of all experience and meaningmaking (Merleau-Ponty, 2002; Johnson, 2007).

\section{Multi-stable musical experiences: African polyrhythm}

Students tend to enjoy exploring the Necker Cube and similar images, as well as the analyses, discussions and speculations that ensue. But while the image of the Cube provides a convenient way to begin developing a phenomenological perspective, its utility is limited and it quickly becomes time to examine more complex phenomena that engage us in the more explicitly embodied, affective and intersubjective ways I have just described. A relatively easy jump can be made from the more abstract experience of the Necker Cube to the living world of musical practice through the introduction of multi-stable musical phenomena such as repeating polyrhythms. These are roughly analogous to the visual example of the Necker Cube in that they are comprised of patterns whose relations may be experienced in multiple ways (Christensen, 2012). Consider the example in Figure 3, a partial representation of the Adowa rhythms played by the Ashanti people of Ghana in West Africa (see Hartigan, 1995, p.33-56). When I work on these rhythms with drum-kit students I choose groups of two or three rhythms, play them together and ask the student to attend to them in various ways. For example, the combination of the dawuro 2 and the donno 1 rhythms creates a simple 3:2 (hemiola) relationship that many students will have experienced previously (the " 2 " pulse is a represented as dotted quarter notes in the donno 1, while the " 3 " pulse is represented as quarter notes in the dawuro 2). However, many students soon discover that the way they initially experience the two pulses is limited to a certain culturally sedimented way of listening. Indeed, Westerners are accustomed to encountering triplets over binary groupings or duple subdivisions of a central beat-i.e. "3" "against" or "over" the grounding " 2 ;" we experience this both in how we listen to music and represent it in notation. Factors such as tempo and relative dynamics and timbre of the pulses may bias perception towards the " 3 " pulse (see Handel, 1984). But whatever the case, we in the West often tend towards a hierarchical perception of polyrhythm, where one pulse is often understood as central - a conditioned representation that African musicians would not necessarily share. And indeed, one of the reasons I choose to introduce these rhythms early on with drum students is because they offer an opportunity to discuss other cultural alternatives to the taken-for-granted ways of thinking about and perceiving meter, rhythm and time keeping 
in the West (this may help students better understand their own naturalized ways of listening and doing and thus begin the process of discovering new possibilities).

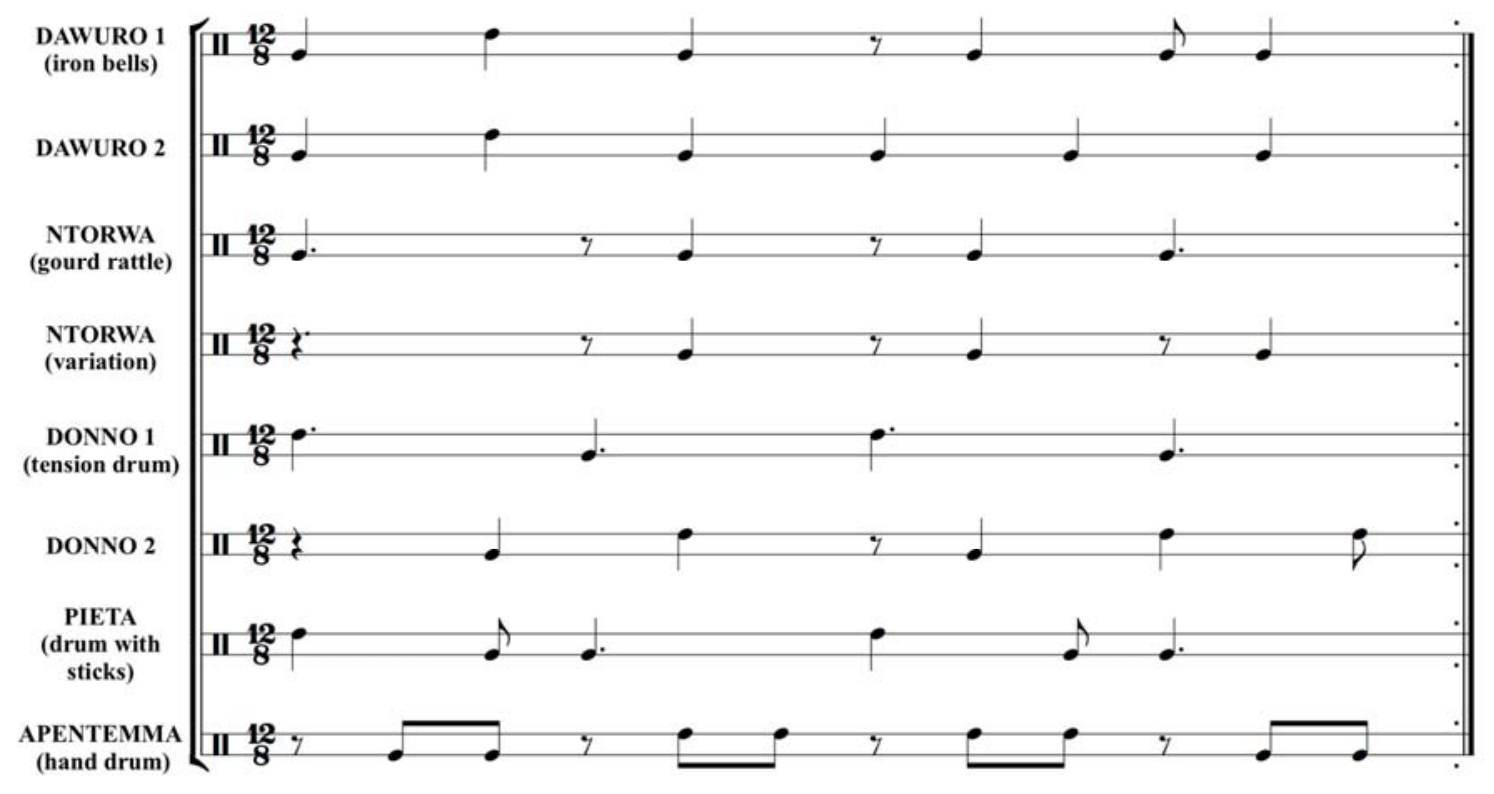

https://soundcloud.com/dylan-van-der-schyff/adowa-rhythm-study-for-phenomenology-practice

Figure 3. West African rhythms (adapted from Hartigan, 1995, p.33). ${ }^{4}$

Students are asked to shift the focus of their attention between the two pulses, maintain a "neutral" position between the two, and to attend to how the experience develops. They recognize this as somewhat analogous to developing the possibilities of the Necker Cube, and may draw on the insights into the structure and modes of experience that exercise offered. The "flipping" back and forth between the up and down position of the Cube image is recalled by alternatively attending the " 3 " and " 2 " (or "slow" and "fast" perhaps) perspectives of the polyrhythm. Likewise, both pulses may be encountered equally, which may be seen as analogous to developing the "flat" (or 2D) experience of the Cube. The addition of more complex rhythm, such as the ntorwa, develops things further. As the new rhythm emerges against the background polyrhythm, students see how they can transform the experience of this rhythm depending on which of the other pulses they associate with it. For example, the dotted quarter pulse of the donno 1 pattern with the ntorwa maintains a hemiola quality. However, in

\footnotetext{
${ }^{4}$ The sound file demonstrates the 3:2 pattern and some of the Adowa rhythms presented here. Listeners will first hear the bass drum playing the "2" associated with the donno 1 and the cross-stick playing the " 3 " associated with the dawuro 2. The tom-tom drums enter playing a simplified version of the donno 2 pattern. Shortly after this the cowbell and bongo drum add variations of the ntorwa and apentemma, respectively; and the dawuro 1 is introduced on a woodblock. A maraca is also added to reinforce the " 2 " of the bass drum. The sound file concludes with an improvisation on a high drum. It should be noted that this example uses Western percussion instruments; a traditional African ensemble will sound quite different. Also, these patterns are usually played at a much faster tempo and a number of additional rhythms are involved. Listeners may tap along, first with the " 2 " of the bass drum, and then with the " 3 " of the cross stick. Following this they may try using both hands and/or feet to play both pulses along with the example, or even attempt to play some of the rhythms simultaneously. In doing so one might explore some of the phenomenological insights discussed above.
} 
association with the quarter notes of the dawuro 2 pattern, the relationship takes on a distinctly even eighth note flavor. As before, students are asked to bring the various rhythms and combinations of rhythms to the foreground (the focus); to clap one of the rhythms while I play the others; to move between states of absorption, reflexivity and analysis; and to note the developments in the experience. They are also encouraged to develop evolving narratives of the experience - to describe the aesthetic effect of the combinations of rhythms with metaphors of movement, tension, space and location (e.g. speed, density, position in a rhythmic landscape; see Johnson, 2007). Most importantly, students are asked to embrace the inherent ambiguity and multiplicity in how these patterns may be experienced, and to reflect on how such experiences are enacted and developed through their own agency.

This work becomes even more interesting when students begin to practice such rhythms themselves. As students work to simultaneously develop the physical coordination and aesthetic understandings that will allow them to enact the various rhythms individually and in various combinations, they are required to break from habitual ways of thinking about and physically interacting with their instrument. For kit drummers this challenge involves incorporating the bodily extremities - the feet and hands must work together and independently; the voice may be included as a fifth element. This phase of learning is generally accompanied by a certain amount of discomfort and frustration. Interestingly, what makes this initial process of exploration so uncomfortable is precisely what makes it so informative.

Here students are confronted with a diverse range of new focal points and relationships that must be attended to and advanced reflexively without losing contact with the larger musical-polyrhythmic context from which they emerge. These are spread across the audible, visual, bodily, and abstract fields of experience; and each may reveal naturalized inclinations that must be identified and developed. The phenomenological attitude encourages the student and teacher not to ignore or rush through this process, but rather to attend to it carefully. Initially the experience is frustratingly disjointed and the awareness of one's own body and its relationship to the new musical environment it is involved in creating is uncomfortable. However, a reflexive analysis of this state may help the student become more aware of the body's proclivities - its sedimented ways of doing and being - and thus develop more nuanced ways of experiencing their embodied musicality. In the process, students may begin to see that what was once taken-for-granted as "naturalized" may be better understood as a historical process of embodied and conceptual sedimentation; and that new possibilities may emerge with sustained phenomenological work-new musical worlds in which they may come to feel increasingly "at home."

Once again, students are asked to shift and share the focus of attention between various bodily, auditory and musical relationships as they play more complex three or four part groupings; and to incorporate the musical activities of others into the shared musical ecology (Reybrouck, 2005). Students may also be encouraged to explore the various and shifting relationships they enact between the musical tools they employ. That is, how new forms of awareness (and extensions of "self") may occur through "instrument-embodied perceptions" (Heelan, 1967; and Ihde, 1974). ${ }^{5}$ In doing so, they may come to better understand the central role the body plays in enacting the (musical) worlds they inhabit (Benson, 2001; Gallager, 2005; Johnson, 1987, 2007; Merleau-Ponty, 2002; Nöe, 2006; Sheets-Johnstone, 1999). Additionally, such investigations might also open deeper insights into the situated and intersubjective (or extended) nature of cognition, learning and musical meaning-making-including the primordial forms of the "aesthetic" and "participatory" sense-making I began to discuss above (De Jaegher \& Di Paolo, 2007; Johnson, 2007; Krueger, 2013, 2014). In brief, the cultivation of a phenomenological attitude may help students better understand and discuss the embodied

\footnotetext{
${ }^{5}$ See also Heidegger's notions of present-to-hand and ready-to-hand, and equipment; Heidegger, 1962; Blattner, 2006, Dreyfus, 1991).
} 
and dynamically relational nature of musical experience. That is, how the evolving experience of the musical ecology is characterized by the ongoing interactivity between one's own actions and thoughts, and the tools, spaces and other agents that co-constitute it (Borgo, 2005, 2007; Mathews, 2008; Reybrouck, 2001, 2005, 2012).

As students develop richer phenomenological skills and understanding they gain the ability to orient themselves within the music from different perspectives and in a controlled manner. They may now play with different interacting, and embodied musical relationships (e.g. sonic-environmental, embodied-instrumental, interpersonal and abstract) and learn to reflect creatively on what they are doing as they do it-i.e. to play "in the moment." In this way students may be encouraged to develop the ability to fluently shift and share attention between multiple focal points; to imagine and develop new relationships with greater ease; to improvise; and to become more mindful of the process of musical experience as creative agents - crucial skills for the development of high-level musicianship. Indeed, it is extremely rewarding for students when they begin to realize that they are capable of imagining and enacting multiple approaches to their musical experiences and activities. They now begin to "look" at familiar musical experiences in a new light; and may be encouraged to develop the phenomenological attitude, as well as other approaches to reflective practice and mindful-awareness across the range of their musical practice (Biswas, 2011; Gibbs, 1998; Lowe, 2011; Lyons, 2010; Gyamtso, 1986; Sarath, 2006; van der Schyff, 2015). ${ }^{6}$ In doing so they may begin to discover that the path to musicality does not lie in fixed approaches and sedimented ways of acting and thinking, but rather in flexibility, freedom, the ability to maintain multiple perspectives - in a kind of open-minded readiness to participate reflexively and imaginatively in an ongoing process of relational and transformative experience (Small, 1999; Bateson, 1979/1980).

\section{Conclusion}

Due to restrictions of space I have given here only a brief sketch of what phenomenological analysis entails. Readers familiar with the phenomenological literature will note that I have basically adopted a simplified Husserlian/Merelau-Pontian approach - these core ideas offer a good place to begin phenomenology, even if eventually other approaches become more relevant to the inquiry at hand. Moreover, the speculative examples of phenomenological analysis I have offered have been abbreviated; and my practical examples have been limited to one (important) aspect of my practice as a music educator. Other writers have offered related analyses from different musical perspectives (e.g. Clarke \& Clarke, 2011; Christensen, 2012; DeNora, 2000; Ferrara, 1984; Ihde, 1976; Krueger, 2009, 2011a\&b; Pio \& Varkoy, 2015; Sudnow, 1978; Small, 1999; Roholt, 2014). Additionally, a number of excellent introductory texts have appeared in recent years that may help readers gain a wider perspective of the relevance of phenomenology across a range of domains (e.g. Gallagher, 2012; van Manen, 2014). This said, I hope that what I have discussed here will resonate in various ways with broader aspects of musical experience and learning. At the very least, I hope it will provide a useful introduction to the kinds of insights phenomenology may afford with regard to the project outlined in the introduction-namely, the challenge music and arts educators face in getting students to

\footnotetext{
${ }^{6}$ The Alexander technique is also relevant here. This practice involves becoming more mindful about one's movement and posture, with the goal of revealing and correcting unhealthy habits and promoting well-being (see Gelb, 1996).
} 
become more aware of their active participation in the process of embodied aesthetic experience. $^{7}$

For philosophers, phenomenology offers ways of exploring the structure of experience and developing new knowledge about it. Likewise, researchers in psychology and the social sciences may employ phenomenological methods to include first person perspectives in qualitative empirical research. For artists, musicians and arts educators, however, phenomenology may be explored directly in the context of creative (pedagogical and aesthetic) praxis. As I have considered, fostering a phenomenological perspective may aid in developing a certain open, reflective and agentic attitude towards experience - an attitude that every artist must cultivate in someway or another if they are to open themselves up imaginatively to the world and thus participate effectively as the cultural agents they are. In line with this, I have discussed the ways phenomenological reflection can help us better understand how meaningful relationships may be developed and transformed through a structuring and restructuring of the equivocal (e.g. multi-stable phenomena; Merlau-Ponty, 2002). Such a process is central to all imaginative and creative activity. Indeed, the arts "practice possibility" (Ihde, 1977) through imaginative aesthetic explorations of auditory, visual, spatial, linguistic, bodily-kinetic, and self-world interactions (Bowman \& Powell, 2007; Johnson, 1987, 2007). They naturally develop their own forms of suspension (epoché) of the taken-for-granted. And they strive to instill a sense of transformation - new ways of seeing, hearing, feeling doing and understanding that often "shock" us out of our more complacent modes of being-in-the-world (Greene, 1995).

With this in mind, I would like to conclude by pointing out that the phenomenological approach to musical practice I have begun to develop here may be extended well beyond the private lesson, the practice room, or performance situations. This is to say that practice-based approaches to phenomenological inquiry in the arts may in fact serve as the foundation for more far-reaching, comparative and critical investigations into the discourses and activities that constitute self and society. For example, as I suggested earlier, the West African rhythms considered above might be employed to initiate a discussion and exploration of differences in how music is understood and used in other cultures. Along these lines, a growing number of writers are developing phenomenologically based approaches to the experience of culture and self (e.g. Benson, 2001). Such work may further aid students in moving beyond sedimented ways of understanding the socio-cultural milieu they participate in; it may afford them an opportunity to consider their own cultural relationships more deeply - and with a more critical eye - and to imagine transformative possibilities for creative expression. This might result, for instance, in new conceptions of what constitutes an "ensemble", or new ways of collaborative composing. It might also inspire a deeper interest in integrating music with other expressive and academic disciplines - e.g. social-cultural studies, perhaps in conjunction with forms of critical multi-modal media analysis (see Kress \& van Leeuwen, 2001; Machin, 2010).

Perhaps most importantly, the phenomenological attitude also has important ethical and critical implications when it seeks to develop richer and more authentic ways of being-in-theworld (Heidegger, 1962). Indeed, by encouraging our students to open up to the interpretive, creative or, indeed, enactive nature of their own embodied consciousness we may help them see that what is often taken as "normative" is in fact a product of various sedimented sociocultural relations or "conditioning" that may be re-conceived in new ways (Krishamurti, 1970; Nakagawa, 2000; see also De Jaegher, 2013). In this way, the phenomenological attitude also resonates strongly with the so-called praxial philosophy of music education, which sees music education as a deeply social and cooperative activity that is (ideally) concerned with human

\footnotetext{
${ }^{7}$ I would also like to point out that much of what I have considered above resonates with the remarkable insights and practices introduced by the composer, R.M. Schafer $(1986 ; 1994)$, whose pioneering work in 'soundscape studies' is highly relevant in pedagogical contexts. Readers who wish to develop the phenomenological attitude further in sonic-musical contexts will find much that is useful here.
} 
flourishing (Elliott \& Silverman, 2015; Higgins, 2012; Silverman, 2012). By this light, the phenomenological insights students develop in their musical studies may be extended to the broader context of their social and cultural life-worlds. This may help them develop more empathic relationships with the people, things and the "natural" ecology that make our lives possible (Mathews, 2008; van der Schyff, 2015). With this in mind, the phenomenological attitude may also inspire a more general life-affirming orientation that seeks to continually renew itself though imagination and the exploration of new ways of thinking and being.

[...] the human mind thrives on variation, even as it seeks unification; and imagining, more than any other mental act, proceeds by proliferation: it is the primary way in which the mind diversifies itself and its contents. Mind is free - indeed most free-in imagining. (Casey, 2000, p. 200)

In brief, phenomenology and the arts ask us to open up to the world as we find it and develop new ways of perceiving, understanding and communicating our experience as the embodied, social and cultural beings we are. They both demand that we confront the limitations imposed by our complacent and taken-for-granted attitudes and look towards the possible. Greene (1995) reminds us that it is this releasing of the imagination - this critical embracing of the possible, the heterogeneous, and the transformative - that is so central to the role of the arts in education. And indeed, as Casey's words convey so well, it is precisely in those moments when we catch ourselves in the creative act of imagining, restructuring and transforming our experience of the world that we may truly sense what freedom means.

\section{Acknowledgements}

I would like to thank the editors of Phenomenology and Practice, as well as the anonymous reviewers for their useful suggestions. I would also like to thank Andrea Schiavio for reading and commenting on an early draft of this paper.

\section{References}

Attneave, F. (1971). Multistability in perception. Scientific American, 255(6), 63-71.

Bai, H. (2001). Zen and the art of intrinsic perception: a case of haiku. Can. Rev. Art Edu. 28, $1-24$.

Bai, H. (2003). Learning from Zen arts: a lesson in intrinsic valuation. J. Can. Associ. Curricu. Stud. 1, 1-14.

Benson, C. (2001). The cultural psychology of self: Place, morality, and art in human worlds. London: Routledge.

Bateson, G. (1979/1980). Mind and nature: A necessary unity. New York, NY: Bantam Books.

Biswas, A. (2011). The music of what happens: mind meditation and music as movement. In D. Clarke \& E. Clarke (Eds.), Music and Consciousness: Philosophical, Psychological, and Cultural Perspectives (pp.95-110). Oxford: Oxford UP.

Blattner, W. (2006). Heidegger's "Being and Time": A reader's guide. London: Continuum.

Bohlman, P. (1999). Ontologies of music. In N. Cook \& M. Everist (Eds.) Rethinking Music (pp. 17-34) Oxford: Oxford UP. 
Borgmann, A. (1984). Technology and the character of contemporary life: A philosophical inquiry. Chicago: University of Chicago Press.

Borgo, D. (2005). Sink or swarm: Improvising music in a complex age. New York: Continuum.

Borgo, D. (2007). Free jazz in the classroom: An ecological approach to music education. Jazz Perspectives, 1(1), 61-88.

Bowman, W. (2004). Cognition and the body: perspectives from music education. In L. Bresler (Ed.) Knowing Bodies, Moving Minds: Toward Embodied Teaching and Learning (pp.29-50) Netherlands: Kluwer Academic Press.

Bowman, W. \& Powell, K. (2007). The body in a state of music. In L. Bresler (Ed.) International Handbook of Research in Arts Education (pp. 1087-1106). Dordrecht, The Netherlands: Springer.

Carman, T. (2008). Merleau-Ponty. London: Routledge.

Casey, E. (2000). Imagining: A phenomenological study. Bloomington: Indiana UP.

Christensen, E. (2012). Music listening, music therapy, phenomenology and neuroscience. PhD Thesis, Aalborg University, Denmark.

Clayton, M., Herbert, T. \& Middleton, R. (Eds.) (2012) The cultural study of music. London: Routledge.

Clarke, E.F. (2005). Ways of listening: An ecological approach to the perception of musical meaning. New York: Oxford UP.

Clarke, D. \& Clarke, E. (Eds.) (2011). Music and consciousness: Philosophical, psychological, and cultural perspectives. Oxford: Oxford UP.

Clifton, T. (1975). Some comparisons between intutitive and scientific descriptions of music. Journal of Music Theory 19 (1), 66-110.

Clifton, T. (1976). Music as constituted object. Music and Man 2, 73-98.

Clifton, T. (1983). Music as heard. A study in applied phenomenology. New Haven: Yale University Press.

Colombetti, G. (2014). The feeling body: Affective science meets the enactive mind. Cambridge, MA: MIT Press.

Creswell. J.W. (2014). Qualitative inquiry and research design: Choosing among five approaches. Thousand Oaks, CA: Sage Publications.

Damasio, A. (1994). Descartes' error: Emotion, reason and the human brain. New York: G.P. Putnam's Sons.

Davies, S. (2001). Musical works and performances. Oxford: Oxford UP.

Dennett, D. (2002). Quining qualia. In D. Chalmers (Ed.), Philosophy of Mind: Classical and Contemporary Readings (pp. 226-46). Oxford: Oxford UP.

Dewey, J. (2005). Art as experience. New York: Pedigree Trade.

De Jaegher, H. (2013). Rigid and fluid interactions with institutions. Cogn. Syst. Res. 25-26, 19-25. doi: 10.1016/j.cogsys.2013.03.002 
De Jaegher, H., and Di Paolo, E. A. (2007). Participatory sense-making: an enactive approach to social cognition. Phenom. Cogn. Sci. 6, 485-507. doi: 10.1007/s11097-007-9076-9

DeNora, T. (2000). Music in everyday life. New York: Cambridge UP.

Dreyfus, H. (1991). Being-in-the-world: A commentary on Heidegger's Being and Time, Division I. Cambridge, MA: MIT Press.

Dreyfus, H. (1997). Highway bridges and feasts: Heidegger and Borgmann on how to affirm technology. Proceedings of the Conference on After Postmodernism. Available online: http://www.focusing.org/apm papers/dreyfus.html

Dreyfus, Hubert \& Kelly, Sean D. 2011. All things shining: Reading Western classics to find meaning in a secular age. New York: Simon and Schuster.

Elliott, D. \& Silverman, M. (2015). Music matters (second edition). Oxford: Oxford UP.

Fantasia, V., De Jaegher, H. \& Fasulo, A. (2014). We can work it out: an enactive look at cooperation. Frontiers in Psychology, 5, doi: 10.3389/fpsyg.2014.00874

Ferrara, L. (1984). Phenomenology as a tool for musical analysis. Musical Quarterly, 70 (3), 355-373.

Gallagher, S. (2005). How the body shapes the mind. Oxford: Oxford UP.

Gallagher, S. (2012). Phenomenology. New York: Palgrave Macmillan.

Gelb, M. (1996). Body learning: An introduction to the Alexander technique. New York: Holt.

Gibbs, G. (1988). Learning by doing: A guide to teaching and learning methods. London: Further Education Unit.

Greene, M. (1995) Releasing the Imagination. San Francisco: Jossey-Bass.

Gyamtso, K. T. (1986). Progressive Stages of Meditation. Oxford: Longchen Foundation.

Handel, S. (1984). Using polyrhythms to study rhythm. Music Perception, 1(4), 465-484.

Hartigan, R. (1995). West African rhythms for the drumset. Van Nuys, CA: Alfred Publishing Co.

Heelan, P. (1967). Horizon, objectivity and reality in the physical sciences. International Philosophical Quarterly, 7(1), 375-412.

Heidegger, M. (1962). Being and time. New York: Harper and Row.

Higgins, C. (2012). The impossible profession. In W. Bowman and A. L. Frega (Eds.) The Handbook of Philosophy in Music Education (pp. 213-230). New York: Oxford UP.

Husserl, E. (1960) Cartesian meditations. Dordrecht: Kluwer.

Husserl, E. (1962). Ideas: General Introduction to Pure Phenomenology. New York: Collier Books

Husserl, E. (1970). The crisis of European sciences and transcendental philosophy. Evanston: Northwestern UP.

Husserl, E. (1991). On the Phenomenology of the consciousness of internal time (1893-1917). edited and translated by J.B.Brough. Dordrecht: Kluwer.

Ihde, D. (1976). Listening and voice: A phenomenology of sound. Athens, Ohio: Ohio UP.

Ihde, D. (1974). The experience of technology. Cultural Hermeneutics, 2(1), 267-269. 
Ihde, D. (1977). Experimenta l phenomenology: An Introduction. New York: G.P. Putnam's Sons.

Iser, W. (1980). The act of reading. Baltimore: Johns Hopkins UP.

Johnson, M. (1987). The body in the mind: The bodily basis of imagination, reason, and meaning. Chicago: University of Chicago press.

Johnson, M. (2007). The meaning of the body: Aesthetics of human understanding. Chicago: University of Chicago Press.

Kalupahana, D. (1987). Principles of Buddhist psychology. Ithaca: State University of New York Press.

Kress, G. \& van Leeuwen, T. (2001). Multimodal discourse. London: Arnold.

Krishnamurti, J. (1970). Think on these things. New York: Harper Collins.

Krueger, J. (2009). Enacting musical experience. Journal of Consciousness Studies, 16, 98123.

Krueger, J. (2011a). Doing things with music. Phenomenol. Cogn. Sci. 10, 1-22.

Krueger, J. (2011b). Enacting musical content. In R. Manzotti (Ed.) Situated Aesthetics: Art Beyond the Skin (pp. 63-85). Exeter: Imprint Academic.

Krueger, J. (2013). Empathy, enaction, and shared musical experience. In T. Cochrane, B. Fantini, and K. Scherer (Eds.) The Emotional Power of Music: Multidisciplinary Perspectives on Musical Expression, Arousal, and Social Control (pp. 177-196). Oxford: Oxford UP.

Krueger, J. (2014). Affordances and the musically extended mind. Frontiers in Psychology, 4:1003. doi: $10.3389 /$ fpsyg.2013.01003

Leman, M. (2007). Embodied music cognition and mediation technology. Cambridge, MA: MIT Press

Lines, D. (2005a). Blacking's legacy: The transformational and affective dimension of music education. In, V. Rogers \& D. Symons (Eds.) The legacy of John Blacking: Essays on Music, Culture and Society. Perth, Australia: UWA Press.

Lines, D. (2005b). 'Working with' music: a Heideggerian perspective of music education. Educational Philosophy and Theory, 37(1), 63-73.

Lowe, B. (2011). 'In the heard, only the heard...': music, consciousness, and Buddhism. In In D. Clarke \& E. Clarke (Eds.), Music and Consciousness: Philosophical, Psychological, and Cultural Perspectives (pp.111-136). Oxford: Oxford UP.

Lyons, N. (2010). Handbook of reflections and reflective inquiry: Mapping a way of knowing for professional reflective inquiry. New York: Springer.

Machin, D. (2010). Analyzing popular music: Image, sound, text. Thousand Oaks, CA: Sage.

Maturana, H.R. \& Varela, F.J. (1998). The tree of knowledge: The biological roots of human understanding. London: Shambhala.

Matyja, J., \& Schiavio, A. (2013). Enactive music cognition. Constructivist foundations, 8, 351-357.

Mathews, F. (2008). Thinking from within the calyx of nature. Environmental Values, 17(1), 41-65. 
Merleau-Ponty, M. (2002). Phenomenology of perception. London: Routledge.

Morris, B.B (1971). Effects of order and trial on Necker cube reversals under free resistive instructions. Perceptual and Motor Skills, 33(1), 235-240.

Nakagawa, Y. (2001). Education for awakening: An Eastern approach to holistic education. Brandon VT: Education Renewal.

Necker L.A. (1832) Observations on some remarkable phenomenon which occurs in viewing a figure of a crystal or geometrical solid. London and Edinburgh Phil Mag J Sci 3, 329337.

Nöe, A. (2006). Action in perception. Cambridge, MA: MIT Press.

Pio, F. \& Varkoy, O. (2015). Philosophy of music education challenged: Heideggerian inspirations. London: Springer.

Polyani, M. (1969). Knowing and being. Chicago: University of Chicago Press.

Raffman, D. (1993). Language, music and mind. Cambridge, MA: MIT Press.

Reybrouck, M. (2001). Biological roots of musical epistemology: functional cycles, umwelt, and enactive listening. Semiotica 134, 599-633.

Reybrouck, M. (2005). A biosemiotic and ecological approach to music cognition: event perception between auditory listening and cognitive economy. Axiomathes 15, 229-266.

Reybrouck, M. (2012). Musical sense-making and the concept of affordance: an ecosemiotic and experiential approach. Biosemiotics 5, 391-409.

Roholt, T.C. (2014). Groove: A phenomenology of rhythmic nuance. New York: Bloomsbury.

Sarath, E. (2006). Meditation, creativity, and consciousness: charting future terrain within higher education. Teach. Coll. Rec. 108, 1816-1841. doi: 10.1111/j.14679620.2006.00763.x

Schafer, R.M. (1994). The soundscape: Our sonic environment and the tuning of the world. Rochester, VT: Destiny Books.

Schafer, R.M. (1986). The thinking ear: Complete writings on music education. Bancroft, ON: Arcana Editions.

Sheets-Johnstone, M. (1999). The primacy of movement. Amsterdam: John Benjamins.

Silverman, M. (2012). Virtue ethics, care ethics, and "The good life of teaching". Action, criticism, and theory for music education, 11(2), 96-122.

Small, C. (1999). Musicking: The meaning of performing and listening. Middletown, CT: Wesleyan UP.

Sokolowski, R. (2000). Introduction to phenomenology. Cambridge: Cambridge UP.

Solomon, R.C. (1977). Husserl's concept of the noema. In F. Elliston and P. McCormick (Eds), Husserl: Expositions and Appraisals (pp. 168-181). Notre Dame, IN: University of Notre Dame Press

Sudnow, D. (1978). Ways of the hand: The organization of improvised conduct. Cambridge, MA: Harvard UP. 
24 van der Schyff

Thompson, E. (2007). Mind in life: Biology, phenomenology and the sciences of mind. Cambridge, MA: Harvard UP.

van Manen, M. (1990). Researching lived experience: Human science for an action sensitive pedagogy. Ithaca, NY: State University of New York Press.

van Manen, M. (2014). Phenomenology of practice: Meaning-giving methods in phenomenological research and writing. Walnut Creek, CA: Left Coast Press.

van der Schyff, D. (2015). Music as a manifestation of life: exploring enactivism and the 'eastern perspective' for music education. Frontiers in Psychology, 6:345. doi: 10.3389/fpsyg.2015.00345

Varela, F., Thompson, E., \& Rosch, E. (1993). The embodied mind: Cognitive science and human experience. Cambridge MA: MIT Press.

Woodruff Smith, D. (2007). Husserl. New York: Routledge. 